\title{
Does Cloud-Based Accounting Information System Harmonize the Small Business Needs?
}

\author{
Bambang Agus Pramuka \\ Faculty of Economics and Business \\ Universitas Jenderal Soedirman, \\ Purwokerto, Jawa Tengah Indonesia \\ Margani Pinasti \\ Faculty of Economics and Business \\ Universitas Jenderal Soedirman, \\ Purwokerto, Jawa Tengah Indonesia
}

bpramuka@gmail.com

margani.pinasti@yahoo.co.id

\begin{abstract}
Cloud technology is now becoming a valuable resource, as it provides cost-saving business technology. Businesses exist to earn a profit by keeping their capital and expenses low. In an attempt to address the issue, this study employs structural equation model to complement literature on users' technology acceptance behavior. The framework of the study was based on the technology acceptance model (TAM) to better understand the adoption of cloud computing by small businesses owners. This study looks at the perception and attitudes of small businesses (SMEs) towards cloud technology based accounting information systems, therefore, their intention to adopt the technology. Result support the view that perceived usefulness, ease of use and credibility positively influenced SMEs' attitudes towards cloud-based accounting information systems and therefore their intention to adopt the technology. The result enhances literature in the field of cloud-based accounting systems for small businesses.

Keyword: Cloud computing, Accounting information system, Technology acceptance model
\end{abstract}

\section{Introduction}

Cloud technology has continued growing at unprecedented levels. It is among disruptor in the digital era, which enables small business to create a new market and threaten an existing market. The availability of ubiquitous internet broadband supports the adoption of cloud technology worldwide, which leads to a new economic era that is referred as internet economy [2], [37]. The spillover of internet penetration has reached Indonesia with an astonishing average growth of 29.7\% in 2010-2015. The emergence of cloud business model paradigm brings substantial impact on the way companies do business [11]. Businesses use cloud computing for a variety of objectives, ranging from promotion until for array of goals, ranging from advertising to recording and reporting the business transaction. Small businesses take most 
advantages of cloud computing as it provides low-cost business technology. Preliminary research indicates that growing numbers of SMEs have adopted cloud computing and mobile technologies [21]. Cloud computing also spoils users by fulfilling all their needs at the speed of "eye blinking." The technology can also fulfill a wide range of users' information needs conveniently.

Business organizations must react quickly to the highly intensified competitive pressures by making an accurate decision based on reliable and relevant data [30]. Given the unprecedented radical changes, successful businesses' firms must keep their effort persistent by continuously seeking for new access to useful, authentic and timely information [31]. The manual accounting system is designed for recording and reporting of financial and non-financial information to users for decision-making purposes. One drawback of the manual accounting system is the amount of time an accountant must spend on it. In the absence of computer categorizing and totaling figures, an accountant must perform the work manually. It takes more time to do manual accounting than it does computerized accounting. This creates an opportunity to rethink the accounting systems so it most benefits to users.

To obtain timely, reliable and more accurate financial information, organizations need to develop and adopt accounting methods, functions, and applications [29], [28]. Nonetheless, turbulent changes in business environments followed by technological advances have hampered the ability of the present accounting system to fulfill the financial accounting needs of firms. In the meantime, it is critical to note that the purposeful and decent usage of accounting information systems stimulate a firm to choose the most suitable features of an accounting system. Despite popular publications on different aspects of the accounting system, the congruity between adopted accounting system and the organizations' environment is not as broadly analyzed [30].

Accounting information system (AIS) is a computer-based method for tracking accounting activity in conjunction with IT resources [19]. It assists users in making accurate and timely decision making. To get the most benefits the systems, organizations must choose appropriate IT instruments. Among the advantages of cloud-based AIS are low cost, ease of use and efficient as it can be accessed using a mobile phone. To ensure fast reactions and accurate decision making, firms must progressively look for new opportunities and resources to support their operation.

Research on the adoption of mobile cloud technology in e-commerce are numerous [17], [21], [47]. Nonetheless, limited work is evidenced by the use of cloud computing technology in accounting information systems by small businesses. A small business practitioner can use mobile technologies and applications for several purposes such as Mobile Payments [18], Automatic Documents Entry, Mobile Customer Service, and Mobile Accounting Service [26]. In the light of accounting systems role and structure [24], it is apparent that cloud and mobile technologies remarkably determine accounting information system both from within the organization as well as from the outside [48].

Recent phenomenon of cloud technology adoption for a business transaction is burgeoning in Indonesia, in fact, one of the fastest in Southeast Asia. The euphoria of technological based accounting systems has reached small business organizations due 
to its' perceived costs and benefits. Small businesses (SMEs) in Indonesia are suffering from low financial power [3] as they are still focusing on short term funding to support their working capital. Moreover, most SMEs in Indonesia are not bankable due to low level of trust on their ability to pay their liability [40]. Some of the factors attributable to the low trust is the absence of standardized financial reporting [41]. To date, most SMEs use simple manual booking to record the daily businesses transactions due to poor knowledge and lack of supporting technology. In the meantime, technological development are continuously evolving and affecting every aspect of business life, regardless their size. One area that is strongly affected by technology is accounting and finance. The adoption of e payment increase the speed and reliability of transactions and in later date would enhance the business control over the market [24]. Inevitably, small business should start building network with financial institutions to increase their financial access by preparing standardized financial statement. Therefore, there is a need to understand critical prerequisites that affect small businesses' intention to adopt Cloud technology based accounting systems. The current study seeks to better understand the adoption of cloud computing by SMEs, their perception, and attitudes towards cloud technology based accounting information systems, therefore, their intention to adopt the technology.

\section{Literature Review}

\subsection{Accounting Information System}

Accounting plays a focal function for every business, large or small. Accounting information system (AIS) defined as an information system that can change the business transaction data into useful financial information for both external and internal users. Specifically, AIS is helpful in collecting, maintaining and processing economic data to assist management in decision making [48]. The accounting system can be executed manually or using a computer. In the manual systems, the functions are performed by hand by trained professionals to keep detailed records of businesses' operating activities, revenues cycle and all kind of expenditures associated with it, financing activities and the investing activities of firms within a specified period [48].

To date, AIS is a computer-based system for recording business transactions with the support of information technology resources [19]. The structure of Accounting information system encompasses three subsystems namely: transaction processing system to support daily business operations; general ledger system/financial reporting and management reporting system [23]. The first subsystem aims at automating business processes emphasizing accounting domain as the very first to use information systems to support its activities [47]. The second subsystem summarizes and measures businesses transaction cycle activity followed by reporting the status of financial resources in the form of financial statements or tax returns to external entities [23]. Accounting information system provides useful information to management for decision-making purposes and establishing adequate internal controls [42]. 
Some small business still enjoys the manual process of accounting nowadays, despite its tedious operations, due to its perceived cost savings advantage. Accounting software is costly for those who just started doing a business; to save money the owner can perform the recording process alone using a paper ledger. Other drawbacks of the manual systems are the inability to process transactions at once, every stage in the cycle must be performed manually, low speed and accuracy. In the meantime, a computerized system makes record keeping more comfortable as it offers the benefit of speed and accuracy.

\subsection{Cloud-based Accounting Information Systems}

To date, increasing number of firms adopt mobile and cloud technology as infrastructure to support their businesses activities, including accounting information system. Cloud computing can facilitate software engineering activities with computational, storage and other resources over the network [36]. Past literatures highlight the benefits of using cloud technologies in business in terms of its scalability, mobility and low maintenance costs [11]. Moreover, cloud technology is easy to deploy and it does not require extensive hardware and software infrastructure compared to on-premise accounting information system. There are merits and hurdles of on-premise AIS. Business firms need to invest heavily on installation and maintenance of systems' infrastructure [33] Cloud technology provides access of technology that offers benefits of the on-premise solution in a more affordable way to small business with a restricted budget. Thus, cloud-based systems will become the mainstay of organizations in the future [8], [9], [33], [35].

The size of the firms can be critical in determining cloud vendor. Therefore, the features of cloud services offered. Small, medium enterprises (SMEs) prefer to use low price cloud systems with a minimum cost of investment. The systems make SMEs aptly suited for cloud AIS due to its low costs- as vendors take care of the systems in perpetuity. Previous work by Gupta, Seetharaman, and Raj [21] focus on the perceived inclination of micro and small businesses toward cloud computing and present five factors that influence the usage of cloud computing by small companies: ease of use, security, cost reduction, reliability and sharing, and collaboration. Dinh et al. [17] surveyed the architecture, the applications, and the approaches mobile cloud computing and concluded that the technology overcomes problems related to performance, environment and security. Some drawbacks of the technology are low bandwidth, poor network access management, poor quality of service, high pricing, interfacing and service convergence [17].

A recent study by the Cloud Accounting Institute (2013) suggests that Accounting/Financial Management is currently the most widely deployed cloud solution areas. Around 74 percent of the managers intend to use the software as a service for Accounting/Financial Management solutions. Among the expected benefits of the adoption are simplifying software management, reducing capital and operating costs, and speedy implementation while the top three concerns are related to the security system, compatibility with other applications, total cost, and application performance. Further, the study revealed that the main benefits of 
integrating cloud solutions are one tool for improved management decision-making, reducing duplicate data entry and real-time reporting.

Accounting information systems process and store a series of sensitive data such as financial and customers details as result security and confidentiality risks are the most critical concerns for users [35]. Therefore prior to adopting cloud technology firm must perform a rigorous analysis of the application security. Big firms place a strong emphasis on the safety of their data and information. As a result, they would undergo the due diligence process of selecting vendors that meet requirements which might not be the case for small firms as they are price sensitive. From a global perspective, AIS development using cloud and mobile technologies will lead to a reorganization of the business architecture with significant impact on business strategy [11].

Rapid technological developments have significantly impacted work environments and businesses management. As business environment becoming more dynamic and competitive, it becomes essential for managers to make consistent, logical and strategic decisions and develop instruments and models that provide financial information thus raising the importance of Accounting for organizations [30]. The accounting system is considered as a useful system when it fits and conforms to the environment of the organization.

\subsection{Technology Acceptance Model (TAM)}

The need for predicting system use emerges because of increasing failure rate in technological adoption in organizations [15]. Most of the studies carried out failed to produce reliable measures that could explain system acceptance or rejection [16]. In 1985, Fred Davis introduced the Technology Acceptance Model which is defined as an information systems theory that explains how users finally accept and use technology. Davis [16] believed that system use is a response that can be described or predicted by user motivation. This motivation, in turn, is directly influenced by an external stimulus consisting of system features and capabilities.

Technology acceptance model was developed based on previous Theory of Reasoned Action [7] Theory of Planned Behaviour [6] and other related research studies. TAM is one of the most powerful extensions of Ajzen and Fishbein's theory of reasoned action (TRA) in the literature [14]. The theory of reasoned action says that a person's intentions are the best guide to behavior. If a person intends to do an act, then it is likely that the person will do it. Moreover, a person's intentions are themselves guided by two things: the person's attitude towards the behavior and the subjective norm. To put the definition into simple terms: a person's voluntary behavior is predicted by his/her attitude toward that behavior and how he/she thinks other people would view them if they did the behavior. A person's attitude, combined with subjective norms, forms his/her behavioral intention. TAM replaces many of TRA's attitude measures with the two technology acceptance measures - ease of use, and usefulness [14]. Perceived usefulness (PU) is the degree to which a person believes that using a particular system would enhance a person's job performance while 
Perceived ease-of-use (PEOU) is the degree to which a person believes that using a specific system would be free from the effort [15].

TAM suggests strong correlation exist between individual differences and IT acceptance [5], [50]. Therefore, the Model (TAM) has served as the basis for past researchers on information systems dealing with behavioral intentions and usage of information technology [1], [14], [16], [27], [39]. As a well-recognized theoretical basis for studying user acceptance, TAM [16] proposes that user's perceptions of a system's ease of use and usefulness can influence how quickly and efficiently users will adopt the new technologies. Thus, according to TAM, the more accessible a technique is to use, and the more useful it is perceived to be, the more positive the user's attitude and intention towards using the technology [14].

There are six elements of Technology acceptance models [14]. First, the external Variables (EV) is variables that affect perceived usefulness ( PU), perceived ease of use (PEU), and Attitude toward Using. Perceived Usefulness (PU) which means that a person believes that using the particular system/technology will improve his or her action [50]. Perceived Ease of Use (PEU) which means that a person believes that using the particular system/technology will simplify and not complicated [51]. Attitudes towards use (A) which is defined as the users' desirability to use the particular system/technology; and Behavioral Intention (BI) is forecasted by the attitude towards use (A) combined with perceived usefulness (PU).

\section{Research Model and Hypothesis}

The model of the study was developed based on the theory of TAM. The exogenous variable/independent variables in this research were perceived usefulness, perceived ease of use, and perceived security cloud-based AIS. The Endogenous variables consist of small businesses' attitude and behavioral intention to use the systems. The model is presented in figure 1 .

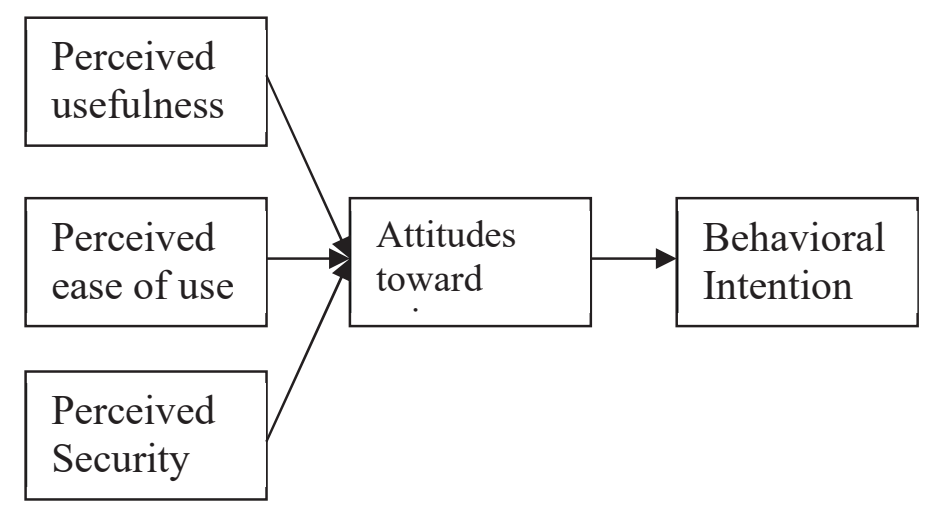

Figure 1. Technology acceptance model of cloud technology based AIS 
The theory of TAM posits the existence of causal relationships between perceived usefulness, perceived ease of use, attitude and behavioral intention in explaining users' acceptance of technologies. Also, bias towards cloud-based accounting information systems is determined by three salient beliefs, namely perceived usefulness and perceived ease of use [16] and perceived security of the systems [35]. Finally, behavioral intention is determined by attitude.

The attitude toward using a given technology is the overall evaluation that predicts a user's likelihood of adopting that emerging technology. Past research indicates that attitude is influenced by both Perceived ease of use and Perceived usefulness components as well as the perceived security of the system [35]. Thus, the following hypothesis is proposed

H1. Perceived usefulness has a positive effect on attitude towards cloud technology based AIS.

H2. Perceived ease of use has a positive effect on attitude towards cloud technology based AIS.

H3. Perceived security has a positive effect on attitude towards cloud technology based AIS.

Based on the theory of TAM, SMEs behavioral intention to adopt cloud technology based AIS is influenced their Attitudes toward it. This relationship has been examined and supported by many prior studies [1], [16], [50]. Therefore, this study presents the following hypotheses.

H4. Attitude has a positive effect on behavioral intention.

\section{Research Methods}

This study used a quantitative method to collect the data to study the factors that influence the adoption of cloud technology based accounting information systems by small business firms in Indonesia. Questionnaires were distributed to the respondents who work as financial officers in small businesses which used cloud technology AIS in recording their business transactions. The sampling technique used was purposive sampling. Only SMEs that uses cloud-based AIS were selected as sample. The total samples involved in this study were 175. The study is not limited to specific brands and operating system of the cloud AIS.

The tool of analysis used was Structural Equation Modeling (SEM) using Analysis of Moment Structure (AMOS 22.0 software). The exogenous variables were perceived usefulness, perceived ease of use, and perceived security while the endogenous variables were the attitude toward using and behavioral intention to use cloud-based AIS. There were seven steps executed during the analysis [22]: developing the model based on theory; creating the path diagram; translating the path diagram into structural equation; choosing the type of matrix input and estimation model proposed; assessing structural model identification; assessing Criteria Goodness of Fit and finally interpreting and modifying the model. Validity testing was performed using convergent validity. Reliability measures the internal 
consistency of constructs' indicators. The reliability test was conducted using composite (construct) reliability and variance extracted.

\section{Research Methods}

\subsection{Description of Respondents}

The respondents came from different business categories namely: fashion, food and beverage, batik, handicrafts, cooperatives, service, and printing. Table 1 presents a description of respondents. As indicated in table 1, the distribution of samples is entirely proportional according to their business cluster. The highest participants come from food and beverages companies amounted to $19.43 \%$.

\begin{tabular}{llll}
\hline No & Business Types & Quantity & Percentage \\
\hline 1 & Fashion & 31 & 17.71 \\
2 & Food and beverages & 34 & 19.43 \\
3 & Batik & 32 & 18.29 \\
4 & Handicrafts & 26 & 14.86 \\
5 & Cooperatives & 18 & 10.29 \\
6 & Services & 14 & 8.00 \\
7 & Printing & 20 & 11.43 \\
\hline & Total & 175 & 100.00 \\
\hline
\end{tabular}

Table 1. Description of the sample based on the type of business

\subsection{Estimation and Model Fit}

The first criterion to be fulfilled was data normality before evaluating the measures of goodness of fit of the model. The result indicates that the data was normal. The univariate analysis was also performed. The result shows that the z-score of the overall indicator forming latent variables in this research was less than or equal to 3 confirming that this research data free from univariate outliers. A separate analysis on multivariate outliers also generated highly consistent results. Multivariate outliers testing indicated that there were no multivariate outliers detected. Table 2 present summary of the goodness of fit of the model tested.

Chi-square value was 357.476 which is higher than the amount of chi-square table of 221.438 , with an error rate of $1 \%$ and the number of sample of 175 , indicating that the model fitting was only acceptable. The probability score was 0.000 which was below the recommended cut of the value of 0,05 suggesting that the model was adequate. The value for Minimum Sample of Discrepancy Function Divide with Degree of Freedom (CMIN/DF) was 1.932 which was less than the recommended cut of the value of 2.00; it indicated a good fit of the model. The goodness of Fit Index (GFI) and Adjusted Goodness of Fit Index (AGFI) are smaller than 0.9 which reflect only an acceptable fit. The Tucker-Lewis Index (TLI) was 0.901 less than the 
recommended cut of the value of 0,95 indicating that the model is fair. CFI was 0.913 below the recommended cut of the value of 0,95. Thus the model was acceptable. Finally, the Root Mean Square Error of Approximation (RMSEA) was 0.073 smaller than the cut of the value of 0.08 ; it indicated a good fit of the model.

\begin{tabular}{cccc}
\hline $\begin{array}{c}\text { Goodness of fit } \\
\text { Index }\end{array}$ & $\begin{array}{c}\text { Cut of } \\
\text { Value }\end{array}$ & $\begin{array}{c}\text { Analysis } \\
\text { Result }\end{array}$ & $\begin{array}{c}\text { Model } \\
\text { Evaluation }\end{array}$ \\
\hline $\mathrm{X}^{2}$ Chi-Square & $<221.438$ & 357.476 & Marginal \\
Probability & $>0.05$ & 0.000 & Marginal \\
CMIN/DF & $<2.00$ & 1.932 & Good \\
GFI & $>0.90$ & 0.834 & Marginal \\
AGFI & $>0.90$ & 0.793 & Marginal \\
TLI & $>0.95$ & 0.901 & Marginal \\
CFI & $>0.95$ & 0.913 & Marginal \\
RMSEA & $<0.08$ & 0.073 & Good \\
\hline
\end{tabular}

Table 2. The goodness of fit of the model tested

\subsection{Validity Test, Reliability Test and Variance Extract}

The loading factor of each indicator under the perceived usefulness, perceived ease of use, perceived security, attitudes towards using and behavioral intention was higher than 0.5 indicating that the indicator fulfilled the convergent validity criteria. Thus all indicators were considered valid. All items had higher loadings on their related factors and low cross-loadings, thus showing good convergent and discriminant validities [22]. The coefficient of reliability of variables perceived usefulness, perceived ease of use, perceived security, attitude toward using and behavioral intention to use cloud technology based AIS were all greater than 0.70 . Table 3 presents the result of validity and reliability test

\begin{tabular}{|c|c|c|c|c|}
\hline Factors & Item & Loading Factor & AVE & Cronbach's alpha \\
\hline & $\mathrm{x} 1$ & 0.718 & 0.813 & 0.945 \\
\hline Perceived & $\mathrm{x} 2$ & 0.888 & & \\
\hline \multirow[t]{3}{*}{ Usefulness } & $\mathrm{x} 3$ & 0.878 & & \\
\hline & $\mathrm{x} 4$ & 0.866 & & \\
\hline & $\mathrm{x} 5$ & 0.803 & 0.798 & 0.952 \\
\hline \multirow{4}{*}{$\begin{array}{c}\text { Perceived } \\
\text { Ease of Use }\end{array}$} & x6 & 0.848 & & \\
\hline & $\mathrm{x} 7$ & 0.788 & & \\
\hline & $\mathrm{x} 8$ & 0.802 & & \\
\hline & $\times 9$ & 0.892 & & \\
\hline & $\mathrm{x} 10$ & 0.853 & 0.621 & 0.863 \\
\hline Perceived & $\mathrm{x} 11$ & 0.777 & & \\
\hline \multirow[t]{3}{*}{ Credibility } & $\mathrm{x} 12$ & 0.640 & & \\
\hline & $\mathrm{x} 13$ & 0.509 & & \\
\hline & $\mathrm{x} 14$ & 0.571 & 0.582 & 0.805 \\
\hline
\end{tabular}




\begin{tabular}{ccccc} 
Attitude & $\mathrm{x} 15$ & 0.694 & & \\
Toward & & 0.751 & 0.670 & 0.892 \\
Using & $\mathrm{x} 16$ & & \\
& $\mathrm{x} 17$ & 0.871 & & \\
Behavioral & $\mathrm{x} 18$ & 0.835 & & \\
Intention to & $\mathrm{x} 19$ & 0.529 & \\
Use & $\mathrm{x} 20$ & 0.705 & \\
& $\mathrm{x} 21$ & 0.568 & \\
\hline
\end{tabular}

Table 3. Item loadings on related factors

As shown in Table 3, all of the composite reliabilities (CRs) and Cronbach's alphas were over 0.7, indicating the scales had good reliabilities [10], [35]. Most of the standard loadings were over 0.70 , and all loadings were significant at the 0.001 level. Also, the average variance extracted (AVE) for each construct was over 0.5, demonstrating that the scales had good convergent validities [20].

\subsection{Hypothesis testing}

The significance of causal relationship in the SEM analysis tested through the null hypothesis that suggests that the coefficient of a causal relationship between variable is equal to null through t-test commonly used in the regression analysis. The model consists of three predictor variables: perceived usefulness, ease of use and security. There are two dependent variables, attitudes towards using behavioral intentions to adopt cloud technology based accounting information systems. The multiple regression analysis is presented in table 4 .

\begin{tabular}{lclcc}
\hline & Variable & C.R. & $\mathrm{t}_{\text {table }}$ \\
\hline Attitude & $<---$ & Perceived_Usefulness & 3.008 & 1.660 \\
Attitude & $<---$ & Perceived_Ease of Use & 4.252 & 1.660 \\
Attitude & $<---$ & Perceived_Security & 4.553 & 1.660 \\
Behavioral_Intention & $<---$ & Attitude & 2.089 & 1.660 \\
\hline
\end{tabular}

Table 4. Standardized Regression Weight for Hypothesis Testing

The critical ratios (CR) for all parameters were higher than the value of $t_{\text {he table. Thus }}$ all the parameter estimates were highly significant. Therefore the result of the study supports the entire hypothesis.

\section{Discussion}

As shown in Table 5 all of our hypotheses were supported. The paths between the rest of the TAM components, including perceived ease of use, perceived usefulness, attitudes and purchase intentions, are all statistically significant as proposed by the TAM. The results support prior research indicating perceived usefulness significantly 
influences an individual's acceptance of technology [16], [51]. Similarly, studies have also found a positive relationship between perceived usefulness and attitude towards purchasing technology [13], [31]. The results also confirm previous works that had examined the TAM framework in a variety of cloud technology solutions such as photo-messaging [25], general social network services [12] and satisfaction with social network service use [46]. Thus, the TAM appears to be a valid theoretical model for explaining small businesses perceptions and reaction toward cloud technology.

Perceived usefulness was positively related to a user's attitudes toward using the cloud-based AIS. These results corroborate previous research results on TAM. Cloud technology, as a fast and convenient communication tool, has successfully attracted Internet users, small business owners with a limited budget. The findings coincide with the past study performed by Tan et al. [47], which highlighted that the more benefits perceived users, the more favorable towards their intention to use it. Technology users place high importance on timesaving, convenience and safety features rendered by online technology as a contrast to offline payment. This study also aligned with literature suggesting perceived ease of use is a direct determinant of usage behavior [16], [32]. For practitioners, understanding perceived ease of use as a key factor in adoption and use is critical, especially during the development stage [34]. One study found simplicity and ease of use ranked in the top three essential criteria for technology adoption [45].

When choosing cloud-based accounting information systems companies entrusted their sensitive information to the vendor. No only firms are happy to share their secrets with others. Therefore, security is a challenge for small businesses too. Vendors of cloud technology are required to implement robust security systems to increased users trusts on their services. This study supports the view that the problem of risk and security of cloud and mobile technologies is critical [11]. Although some authors consider that migration to cloud represents a security improvement, many risks and security problems remain.

Consistent with Ajzen [7], this study found that if an individual has a positive attitude toward a device, they are likely to adopt the technology. Further, once a user, if the individual maintains a positive attitude toward the invention, the more likely he or she is to continue using it. The attitude toward using a given technology is the overall evaluation that predicts a user's likelihood of adopting that emerging technology. Past research indicates that attitude is influenced by both Perceived ease of use and Perceived usefulness components as well as the perceived security of the system [35].

\section{Conclusion}

Increasing popularity of cloud technology adoption is evidenced by growing number of companies adopt such technologies as infrastructure support for their activities. Cloud technology is becoming popular among small businesses due to its high efficiency and low cost. This enormous market potential provides an opportunity for the vendor to develop cloud technology solutions, among it is accounting information systems. Vendor of cloud-based technology is eager to know the determinants of 
users acceptance of the products and services offered. This research suggests that the two components of TAM (perceived usefulness and ease of use), perceived security, are essential determining factors on users' attitude towards using cloud technology based accounting information systems and their behavioral intention to use the technology.

This study makes three contributions. First, it explores user acceptance of cloud technology based in Indonesia, where Internet usage is pervasive but less research is carried out in this field. Second, the study uses the theory of TAM to explain small businesses behavior. Results indicate that SMEs accepted the technology due to their perceived usefulness, perceived ease of use and perceived security of the tool. Third, attitude toward using cloud technology based accounting information system shall determine SMEs behavioral intention to adopt the technology.

For researchers, this study shows that SMEs expect a useful and easy-to-use cloud technology based AIS with high-security warranty from vendor. Additionally, more studies need to be carried forward in the Information Systems and e-commerce in small business context, considering the importance of SMEs contributions in the Indonesian economy.

For practitioners, the research provides some guidelines for improving their products and services to attract and acquire users. They need to offer users a robust infrastructure to support small businesses accounting systems. Many small businesses are not bankable because of lack of ability in preparing standardized financial statements. Concerning usefulness and ease of use, practitioners are expected to provide more efficient and reliable software.

Our research has the following limitations. First, our sample was mainly composed of SMEs located in one region, Purwokerto, Central Java Indonesia. To obtain a comprehensive understanding of the applicability of TAM in cloud technology adoption, the sample can be extended to the other areas or group of community or even large firms. Future studies can include another factor, such as the feeling of enjoyment while using the technology, into the model.

\section{References}

[1] D. A. Adams, R. R. Nelson, \& P. A. Todd. Perceived usefulness, ease of use, and usage of information technology: A replication. MIS Quarterly, 16, 1992, 227-247.

[2] W. R. Adawiyah, "Impression management tactics, work-related behavior and perceived the individual performance of sales clerks: a case of Indonesia." International Journal of Applied Business and Economic Research, Vol.13 No.7, ,2015, pp. 5481-550

[3] W. R. Adawiyah, B. A. Pramuka, Najmudin, D. P. Jati., Green Supply Chain Management and Its Impact on Constructions Sector Small and Medium Enterprises (SMEs) Performance: A Case of Indonesia, International Business Management, Vol. 9 No 6, 2015, pp.1018-1024 
[4] W. R. Adawiyah, and B. A. Pramuka, "Scaling the notion of Islamic spirituality in the workplace," Journal of Management Development, Vol. 36 No. 7, 2017, pp. 877-898.

[5] R. Agarwal and J. Prasad, "Are individual differences germane to the acceptance of new information technologies?", Decision Sciences, Vol. 30 No. 2, 1999, pp. 361-91.

[6] I. Ajzen, The Theory of Planned Behavior. Organizational Behavior and Human Decision Processes, 50, 1991, pp.179-211.

[7] I. Ajzen, \& M. Fisnbein, Attitude-behavior relations: A theoretical analysis and review of empirical research. Psychological Bulletin, 84(5), 888e918, http:// dx.doi.org/10.1037/0033-2909.84.5.888. 1977

[8] A. Aleem, and C.R Sprott, Let me in the cloud: analysis of the benefit and risk assessment of cloud platform, Journal of Finance Crime, Vol 20 no. 1, 2013, 6-24

[9] A. Benlian, and T. Hess, Opportunities and risks of software-as-a-service: Findings from a survey of IT executives, Decision Support Systems, 52, 1, 2011, pp. 232-246, British Library Document Supply Centre Inside Serials \& Conference Proceedings, EBSCOhost.

[10] R. Bagozzi and Y. Yi, On the evaluation of structural equation models. Journal of the Academy of Marketing Science, 16(1), 1998, 74-94.

[11] C. Brandas, O. Megan, and O. Didraga, Global perspectives on accounting information systems: mobile and cloud approach, Procedia Economics and Finance, 20, 2015, 88-93.

[12] M. T. Braun, Obstacles to social networking website use among older adults. Computers in Human Behavior, 29(3), 673e680. http://dx.doi.org/10.1016/ j.chb.2012.12.004. 2013.

[13] M. J. Chae, Clothing \& textiles: Consumer acceptance model of smart clothing according to innovation. International Journal of Human Ecology, 10(1), 23e33. 2010.

[14] F. Cheng-Wei, Applied the Technology Acceptance Model to Survey the mobile-learning adoption behavior in Science Museum, International Journal of Innovation and Scientific Research, Vol. 12 No. 1 Nov. 2014, pp. 22-29.

[15] M. Chuttur, Overview of the Technology Acceptance Model: Origins, Developments, and Future Directions. Indiana University, USA: Sprouts: Working Papers on Information Systems 9(37) http://sprouts.aisnet.org/937. 2009. 
[16] F. D. Davis, Perceived Usefulness, Perceived Ease of Use, and User Acceptance of Information Technology. MIS Quarterly, Vol. 13, No 3, 1989, pp.318-339.

[17] H. T. Dinh, C. Lee, D. Niyato, and P. Wang, A survey of Mobile Cloud Computing-Architecture, Applications, and Approaches, Wireless Communication and Mobile Computing, retrieved from http://onlinelibrary.wiley.com/doi/10.1002/wcm.1203/abstract. 2011.

[18] A. Dubey and D. Wagle, Delivering software as a service. The McKinsey Quarterly, 2007. 6: p. 1-12.

[19] A. Fontinelle, Introduction To Accounting Information Systems. Available from:http://www.investopedia.com/articles/professionaleducation/11/accou nting-information systems.asp. 2013.

[20] C. Fornell, and D. F. Larcker, Evaluating structural equation models with unobservable variables and measurement error. Journal of Marketing Research, 18(1), 1981. 39-50

[21] P. Gupta, A. Seetharaman, JR Raj, The Usage and Adoption of Cloud Computing by Small and Medium Businesses, International Journal of Information Management, No.33, 2013, pp. 861-874.

[22] J. F. J. Hair, R. E. Anderson, R. L. Tatham and W. C. Black, Multivariate data analysis with readings. Englewood Cliffs, NJ: Prentice Hall. 1998

[23] J. A. Hall, Accounting Information Systems. 2010: South-Western Educational Publishing. 840.

[24] P. Hari Adi, F. Wihuda and W. R. Adawiyah, The role of social media browsing intention for behavioral outcomes of young consumers, MarketTržište, Vol. 29, No. 1, 2017, pp. 39-57

[25] D. Hunt, C. Lin\& D. Atkin, Communicating social relationships via the use of photo -messaging. Journal of Broadcasting \& Electronic Media, 58(2), 234e252.http://dx.doi.org/10.1080/08838151.2014.906430. 2014.

[26] R. S. Kaplan and D.P. Norton, Measuring the strategic readiness of intangible assets. Harvard Business Review, 2004. 82(2): p. 52-63.

[27] P. Kenny and D. Tugrul, Exploring technology acceptance for mobile services, Journal of Industrial Engineering and Management4(2): 339-360. 2011

[28] Khatri N. Buckling IT capability in healthcare organizations. Health Services Management Research, Vol. 19 No. 2, 2006, p. 73-9.

[29] D. Khazanchi, Information technology (IT) appropriateness: the contingency theory of fit and IT implementation in small and medium enterprises. Journal of Computer Information Systems, Vol. 45 No. 3, 2005, p. 88-95. 
[30] L. Klovienè and E. Gimzauskiene, The Effect of Information Technology on Accounting System's Conformity with Business Environment: A Case Study In Banking Sector Company, Procedia Economics, and Finance, 32, 2015, $1707-1712$

[31] E. Ko, H. Sung \& H. Yun, Comparative analysis of purchase intentions toward smart clothing between Korean and us consumers. Clothing and Textiles Research Journal, 27(4), 2009, 259-273

[32] H. H. Lee, A. M. Fiore and J. Kim, The role of the technology acceptance model in explaining effects of image interactivity technology on consumer responses. International Journal of Retail \& Distribution Management, 34(8), 2006, $621 \mathrm{e} 644$.

[33] Lenart, A. (2011), ERP in the Cloud- Benefits, and Challenges" Research in Systems Analysis and Design: Models and Methods Lecture Notes in Business Information Procession Vol. 93

[34] A. Lunney, N. R. Cunningham, M. S. Eastin, Wearable fitness technology: A structural investigation into acceptance and perceived fitness outcomes, Computers in Human Behavior 65, 2016, 114-120

[35] S. Marston, S. Li, S. Bandyopadhyay, J. Zhang and A. Chalsasi, "Cloud Computing the business perspective, Decision Support System, Vol 51, 2010 .

[36] J. Münch, Cloud-Based Software Engineering, Proceedings of the Seminar No. 58312107, 05.08.2013, University of Helsinki, Faculty of Science, Department of Computer Science. 2013

[37] A. Nizarudin dan Karmawan, Faktor-Faktor yang Mempengaruhi Niat Adopsi E-Banking pada Nasabah Perbankan di Provinsi Bangka Belitung. Fakultas Ekonomi Jurusan Akuntansi Universitas Bangka Belitung. Ilmiah, Vol. 6, No. 3, 2014, pp. 1-10.

[38] J. C. Nunally, Psychometric theory. New York: McGraw-Hill Book Company. 1978

[39] Amoako-Gayampah, K., and Salam, A. (2003). An extension of the technology acceptance model in an ERP implementation environment. The University of North Carolina at Greensboro, USA: Science Direct Elsevier B.V.

[40] Pinasti, M., and Adawiyah, W.R. (2016), "Co-opetition to promote the growth of batik small and medium enterprises," International Journal of Business and Society, Vol. 17 No. 3, pp. 401-412

[41] N. K. Putri, W. R. Adawiyah and B. A Pramuka, "Independence of audit ethical decision-making process: a case of Indonesia," DLSU Business and Economics Review, Vol. 26 No. 2, 2017, pp. 115-124 
[42] M. Romney and P. Steinbart, Accounting Information Systems. 9th ed. 2003.

[43] A. Rom and C. Rohde, Management accounting and integrated information systems: A literature review. International Journal of Accounting Information Systems, 2007. 8(1): p. 40-68.

[44] A. Rom and C. Rohde, Enterprise resource planning systems, strategic enterprise management systems and management accounting: a Danish study. Journal of Enterprise Information Management, 2006. 19(1): p. 5066.

[45] L. Schooler, Wearable technology future is ripe for growth e Most notably among millennials, says pwc us. 2014. Retrieved October 7, 2015, from http://www. pwc.com/us/en/press-releases/2014/wearable-technologyfuture.jhtml.

[46] B.Shipps \& B. Phillips, Social networks, interactivity, and satisfaction: Assessing socio-technical behavioral factors as an extension to technology acceptance. Journal of Theoretical and Applied Electronic Commerce Research, 2013, 8(1), 35e52.

[47] G. W. H Tan, K. B Ooi, S.C Chong and T. S Hew, NFC mobile credit card: The next frontier of mobile payment? Telematics and Informatics, 2014, 31(2), 292-307.

[48] A. Trigo, F. Belfo, and R. P. Estébanez, Accounting Information Systems: evolving towards a business process oriented accounting, Procedia Computer Science, 2016, 100, 987-994

[49] V. Venkatesh, "Determinants of perceived ease of use: Integrating control, intrinsic motivation, and emotion into the technology acceptance model", Information Systems Research, Vol. 11 No. 4, 2000, pp. 342-65.

[50] V. Venkatesh and F. D. Davis, A theoretical extension of the technology acceptance model: Four longitudinal field studies. Management Science, (46:2), 2000, 186-204.

[51] V. Venkatesh, M. G. Morris, G. B. Davis and F. D. Davis, User acceptance of information technology: Toward a unified view. MIS Quarterly, 425e478, 2013. 